Oregon Undergraduate Research Journal

4.1 (2013) ISSN: 2160-617X (online)

http://journals.oregondigital.org/ourj/

DOI: http://dx.doi.org/10.5399/uo/ourj.4.1.3141

(c) (1)

\title{
Comparing Apis Mellifera and Bombus spp. Pollination Efficiencies on Willamette Valley Blueberry Farms
}

Keane Daly, Miguel Pacheco, Aaron Poplack, Meagan Maxon, Chelsea Johnson, Amanda Whitcomb, Kelsey Kopec, Bret Cypel, Lauren Ward*, Environmental Studies Program

\begin{abstract}
With global honeybee populations declining there is concern for the reproduction of plants, most notably food crops that rely on biotic pollination. The purpose of this study was to monitor the behavior and population size of bumblebees (Bombus spp.) and European honeybees (Apis mellifera) on Highbush Blueberry (Vaccinium corymbosum) farms in the Willamette Valley of Oregon during the spring of 2012. We used these population and behavior studies to calculate the pollination efficiency rates of each bee species. We hypothesized that despite their smaller populations, bumblebees would pollinate much more efficiently than would the European honeybee. To test this hypothesis we measured the effects of farm size and bloom time on the pollination efficiency of each species. To make our assessments, we observed their floral handling rates (defined as the number of flowers visited per minute by a single bee) and took population samples by walking systematically sampled transects on each farm. Our study indicated that bumblebees played an essential role in the pollination of highbush blueberry plants due to their high pollination efficiency rates. Floral handling rates for bumblebees and honeybees were proportional across our two primary variables, (bloom time and farm size) with honeybees pollinating an average of 3.5 flowers per minute and bumblebees pollinating 11.2 flowers per minute. Across all farms, honeybees outnumbered bumblebees by a ratio of 5.8:1. In light of our findings, we recommend that blueberry farmers in the Willamette Valley take steps to increase native bumblebee populations by developing bumblebee-friendly habitat and forage on their farms.
\end{abstract}

\section{INTRODUCTION}

In the last 25 years, scientists have observed sharp declines in global pollinator populations (Pywell et al. 2011). These trends are of great concern because of the importance of pollination as an ecosystem service. Loss of pollinators may contribute to the reduction in plant populations

${ }^{*}$ Authors are members of the University of Oregon Environmental Leadership Program, a collaborative, interdisciplinary service-learning program housed in the University of Oregon Environmental Studies Program. For more information, visit http://envs.uoregon.edu/elp_program/. Please direct correspondence to keane.daly@gmail.com. 
that rely on pollinators for reproduction (Potts et al. 2010). Disappearing pollinator populations and decreasing species diversity have been attributed to a combination of anthropogenic influences including habitat loss and fragmentation (Pywell et al. 2011; Pendergrass et al. 2008), increased pesticide use (Pywell et al. 2011; Pendergrass et al. 2008), agricultural intensification, and introduced pathogens (Rao \& Stephen 2010). The majority of studies cite the synergistic impact of such factors for the diminishing pollinator population. (Potts et al. 2010).

The implications of this decline are especially important in the agricultural sector. There is no efficient method of agriculture pollination without the use of biotic pollinators, most notably bees. Without natural pollinators, pollination efficiency would plummet, greatly affecting agriculture across the world. Historically, non-native European honeybees have been the most commonly used commercial pollinators (Potts et al. 2010; Vaughan et al. 2007). Domestic honeybee stocks in the United States have declined by almost 59\% between 1947 and 2005, making sole reliance on honeybees an uncertain practice (Potts et al. 2010). Honeybee declines have been attributed to a phenomenon called Colony Collapse Disorder (CCD), in which worker bees abruptly disappear. The causes of CCD are not fully understood, but triggers such as Israeli Acute Paralysis Virus (Mader, personal communication 2012), disrupted navigational senses (Boyle 2007), and a new class of insecticide called neonicotinoids (Hopwood et al. 2012) have been studied. With such large reductions in honeybee populations, scientists have proposed that native bees, such as bumblebees in the Willamette Valley, could compensate for lost pollination services (Rao \& Stephen 2010).

Bumblebees tend to pollinate in less favorable conditions and earlier in the season, while honeybees stay in their hives until weather improves (Tuell \& Isaacs 2010). For this reason, bumblebees are well suited to the Northwest where the prime pollination season for blueberries, tree fruits, and native wildflowers is early spring, often characterized by cold and wet weather. Bumblebees also visit more flowers per minute and forage longer each day than honeybees (Steven et al. 2009). Lastly, bumblebees buzz pollinate. Buzz pollination is a highly efficient method in which the bees grasp the anthers of a flower in their jaws and rapidly vibrate their flight muscles to force out pollen (Vaughn et al. 2007).

To further evaluate the pollination services provided by native bumblebees, we compared population abundance and pollination efficiency of honeybees from managed hives, and native bumblebees at six sites in the Southern Willamette Valley. Our study consisted of two surveys concerning pollination counts and floral handling rates. For the pollination surveys, we recorded the total number of each bee species along transects at each farm. We also observed the floral handling rate of three bumblebees and three honeybees on the same transects. We combined our population counts with the floral handling rate to derive the pollination efficiency rates of each species of bee. Our hypothesis is that, while honeybees pollinate more blueberry flowers than bumblebees overall, it is only because of their immensely larger population. We also hypothesize that bumblebees will have much higher pollination efficiency rates than the European honeybee. 


\section{METHODS}

\subsection{STUDY AREAS}

We conducted surveys at six farms located within a 40-kilometer radius of Eugene, Oregon. We classified the farms based on size of blueberry fields. Small farms had less than one hectare (ha) of blueberries $(n=3)$ and large farms had more than one ha $(n=3)$.

\subsubsection{SITE DESCRIPTIONS: SMALL FARMS}

Farm A is located in southeast Eugene, and is managed through conventional farming techniques. The blueberry field size is 0.8 ha contained within one plot. Farm A rents six honeybee hives to provide supplemental pollination services. There are flowering trees on site, along with clovers and grasses between each row. The neighboring properties are flower farms, including a large field of clover. It is unknown whether or not these neighboring farms have honeybee hives.

Farm B is located in North Eugene less than 150 meters from the Willamette River. The blueberry plots are separated into three age groups (40, 25, and 10 year-old bushes) in a field less than 0.5 ha in size. The separation of plots is unrelated to any pollination factors. While the farm itself does not maintain honeybee hives, the neighboring farm has 50 honeybee hives. Farm B has a variety of ornamental flowers and fruit trees along with 1.6 ha planted with a western pollinator seed mix of clover and grasses.

Farm C is located approximately 40 kilometers east of Eugene. The field is 0.8 ha and contains approximately 1,500 plants. The farm has two hives of honeybees and has been managed by the owners of Farm E (see below) for six years. Farm C also grows other crops, including fruits and a number of flowers.

\subsubsection{SITE DESCRIPTIONS: LARGE FARMS}

Farm D is a 5oyear-old farm located in Northwest Eugene. The farm contains 4,400 highbush blueberry plants split into four plots with a total field size of approximately two ha. The plots are separated into three age groups: 50, 25, and 15 year-old bushes. Farm D does not own honeybee hives, but a nearby farm has 27 hives. Blueberry is the only crop on the farm, the remainder of which is 45 ha of unmanaged hay and pasture. The properties nearby grow grapes (Vinus vinifera) and blueberries.

Farm $\mathrm{E}$ is located just east of Eugene and has been cultivating blueberries for 60 years. It has four honeybee hives that are maintained year round. The farm contains 2.2 ha of blueberries and grows 80 other crop varieties interspersed between blueberry rows and on nearby properties.

Farm F is located approximately 35 kilometers east of Eugene. This farm has over 6,000 Vaccinum plants on 2.8 ha and maintains five honeybee hives. The farm is managed no-spray, 
meaning it uses fertilizers but neither herbicides nor pesticides. The farm also utilizes polyethylene fabric for weed control.. There are many flowering plants on the property, including rhododendrons (Rhododendron sp.) and fruit trees.

\subsection{FIELD METHODS}

We conducted our surveys over three separate spring bloom periods - early, mid, and late bloom-between the months of April and May 2012. We classified early bloom as the time when many branches were flowering, with many buds but little to no fruit developing. We defined mid bloom as the time during which most or all branches hade flowers, with many buds and some fruits developing. We described late bloom as the time during which branches had fewer flowers or buds and many developing fruits. We only conducted surveys during optimal weather for pollination activity, with outside temperatures above $15^{\circ} \mathrm{C}$, skies partly cloudy to sunny, and wind speed up to but not exceeding $3.5 \mathrm{~m} / \mathrm{s}$ (Boulay 2012).

We set up transects of $60 \mathrm{~m}$ and $30 \mathrm{~m}$ at the large and small farms respectively. Using a systematic sampling design, we divided the field into equal sections and randomly chose rows within each section. We flagged the beginning and end of each surveyed row with temporary markers to ensure that we visited the same transects during subsequent monitoring. We chose rows separated by eight meters or more to avoid double counting of pollinators. We flipped a coin to determine if we surveyed the left or right side of the bushes. Regardless of total row length, we stopped at $30 \mathrm{~m}$ for small farms and $60 \mathrm{~m}$ for large farms. If rows were too short for a full $60 \mathrm{~m}$ or $30 \mathrm{~m}$ survey, we continued to the same side of the next row while walking in the opposite direction.

Teams of four researchers completed the monitoring surveys. Each team was split into sub teams of two, which focused on either the pollinator population or behavior assessment survey. During behavior assessment surveys, one researcher monitored and identified the bees while the other recorded observations. We walked at a standard pace of three meters per minute. We did not stop the timer to record a dense population of bees pollinating flowers, but slowed down in high-populated areas and quickened the pace in lower populated areas. We used the same transects for both surveys, with a 15minute interval between each survey to minimize bias due to human disturbance. During our surveys, we classified observed pollinators into the categories "bumblebee", "honeybee" or "other." One surveyor counted the number observed and relayed that number to the recorder who kept track of both time and pace to avoid any confusion, double counting or problems with pace.

For the behavior survey, we observed an individual pollinator during a one minute observation period and recorded the number of flowers pollinated. We observed three bumblebees and three honeybees along each transect whenever possible. When not possible, we observed more than three of one type of bee, always resulting in six observed pollinators. We used a Xerces identification pocket guide to accurately identify bees. (Evans 2012). 


\subsection{DATA ANALYSIS}

Our data was used to analyze the influence of farm size and blueberry bloom time on bee population abundance and behavior. These variables were chosen because they were the most distinguishable and influential factors across our provided sites. Because we observed few types of pollinators other than bumblebees and honeybees, we focused our data analysis on those two species. Transects at large farms were twice the length of small farms for more representative coverage. Since the same tactics and planting regimes can be used at small and large farms, the only disparity between sites is the total hectarage. To compare large farms to small farms in spatial terms, we divided their honeybee and bumblebee counts by two.

When calculating population count averages and floral handling rates (defined as the number of flowers pollinated per minute), we combined data across all bloom times, farms, and transects. When analyzing the behavior and population surveys against bloom time, we again pooled data across all farms and transects. It should be noted that the method we used to measure behavior of the bees when three of each species was not available might have skewed the observation count but should not drastically change the overarching results.

By multiplying the average population count with the average floral handling rate we were able to compare the average number of flowers pollinated within transects by both species over a one minute period to determine the bee efficiency rate (see Equation 1). We examined the influence of bloom time and farm size on bee efficiency rates for honeybees versus bumblebees.

$$
B=\beta \times \alpha
$$

where

$\mathrm{B}=$ bee efficiency (average flowers pollinated per minute by total bee group)

$\beta=$ average bee population across all bloom times, farms, and transects

$\alpha=$ average floral handling rate across all bloom times, farms, and transects.

\section{RESULTS}

\subsection{POPULATION SURVEY}

Results are separated into three categories: population survey, behavior survey, and bee efficiency. Honeybees had a total of 1746 counts while bumblebees had only 300 across all farms, which is a ratio of 5.8:1 (Table 1). The ratio of honeybees to bumblebees at the small farms was 18.9:1 as compared to 2.5:1 at the large farms. 
Table 1: Number of pollinators counted on 3 transects at 6 farms after 3 visits during April-May 2012

\begin{tabular}{ccc}
\hline Small Farms & $\begin{array}{c}\text { Honeybee count (total number } \\
\text { of individuals) }\end{array}$ & $\begin{array}{c}\text { Bumblebee count (total number } \\
\text { of individuals) }\end{array}$ \\
\hline Farm A & 451 & 31 \\
Farm B & 289 & 3 \\
Farm C & 414 & 27 \\
Large Farms & & 32 \\
Farm D & 118 & 103 \\
Farm E & 275 & 104 \\
Farm F & 199 & 300
\end{tabular}

\subsubsection{FARM SIZE}

We observed higher ratios of bumblebees to honeybees at small farms than at large farms. The three small farms contained an average of $286 \pm 45.3$ (mean \pm standard deviation) honeybees and $22 \pm 4.5$ bumblebees, whereas the three large farms contained $148 \pm 75.9$ honeybees and $39 \pm 12.8$ bumblebees.

\subsubsection{BLOOM TIME}

Pollinator abundance declined from early to late bloom season across all farms. Early bloom period for blueberry flowers yielded the highest average counts for both honeybees and bumblebees. In early bloom we observed 1261 honeybees and 155 bumblebees. In mid bloom we observed 368 honeybees and 123 bumblebees. In late bloom we observed 117 honeybees and 22 bumblebees. Both families had declining population patterns.

\subsection{BEHAVIOR SURVEY}

The behavior survey measured the number of flowers visited per minute by each bee group. The average floral handling rate from all surveys was $3.5 \pm 1.28$ (mean \pm standard deviation) flowers pollinated per minute per bee for honeybees and 11.2 \pm 1.1 for bumblebees. On average bumblebees pollinated $3.2 \pm 0.5$ times as many flowers as honeybees per minute. 


\subsubsection{BLOOM TIME}

Early bloom had the highest rates of flowers pollinated per minute: 13.5 for bumblebees and 4.6 for honeybees (Figure 1). These numbers gradually declined through mid bloom and into late bloom, in which bumblebees pollinated 6.9 flowers per minute compared to honeybee's 2.5 flowers per minute (Figure 1).

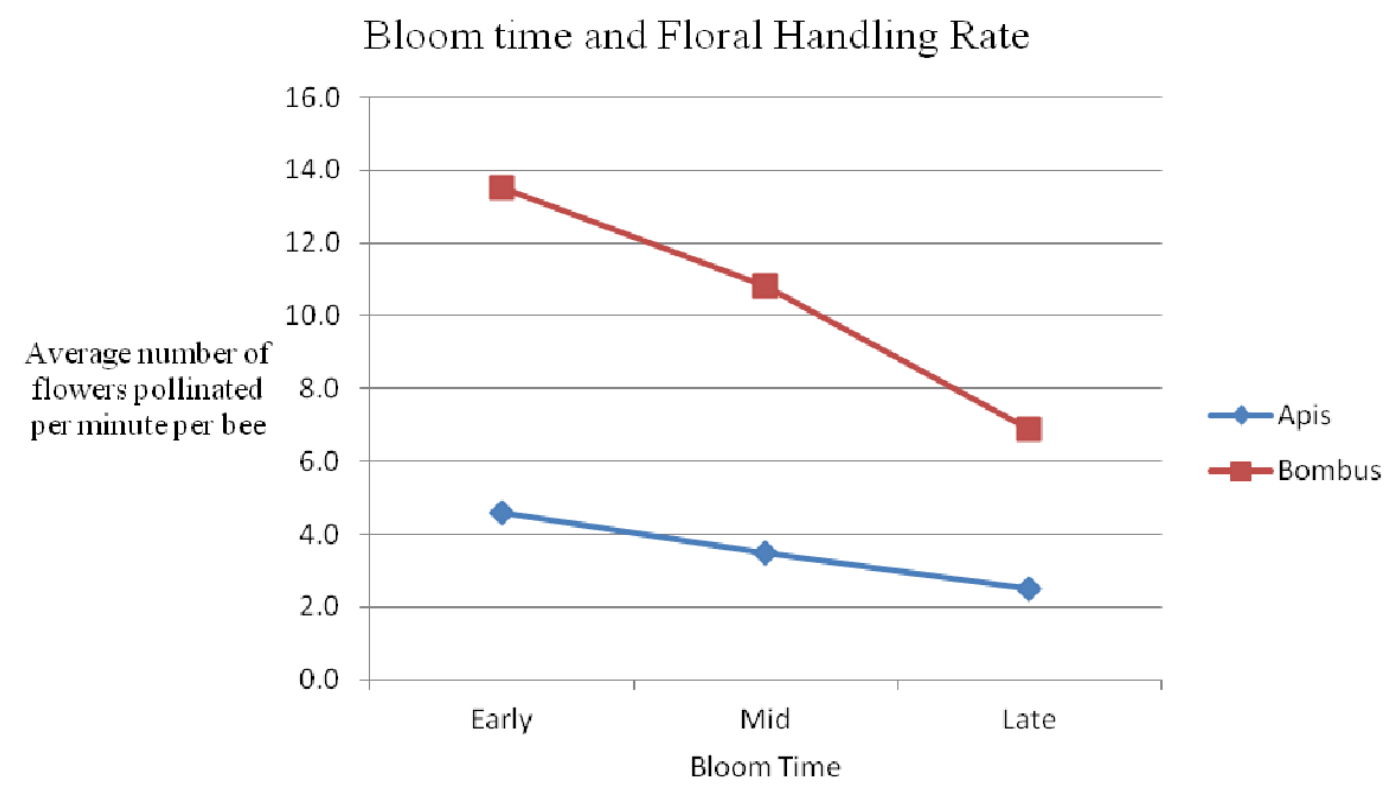

Figure 1: Floral handling rate (number of flowers visited per minute by a single bee) for honeybees (Apis) and bumblebees (Bombus) at 6 farms during April-May 2012.

\subsection{BEE EFFICIENCY}

\subsubsection{FARM SIZE}

Although bumblebee presence was much smaller than honeybee, bumblebees are able to compensate for the number of flowers pollinated with their increased floral handling rate (Equation 1: $B=\beta+\alpha$ ) (Table 2).

Table 2: Bee efficiency (average flowers pollinated per minute by total bee group)

\begin{tabular}{|c|c|c|c|c|}
\hline & \multicolumn{2}{|c|}{ Large Farms } & \multicolumn{2}{|c|}{ Small Farms } \\
\hline & Bumblebee & Honeybee & $\underline{\text { Bumblebee }}$ & Honeybee \\
\hline Population Count & 39 & 148 & 22 & 286 \\
\hline Bee Efficiency & 438 & 521 & 247 & 1007 \\
\hline
\end{tabular}




\subsubsection{BLOOM TIME}

Bumblebees were more efficient over all bloom periods. We determined efficiency by multiplying the bee populations by the average floral handling rate. During mid bloom honeybees were three times more abundant than bumblebees. However, bumblebees were more efficient pollinators as measured by bee efficiency rate (Table 3 ).

Table 3: Bee efficiency (average flowers pollinated per minute by total bee group) during bloom time

\begin{tabular}{ccccccc}
\hline & \multicolumn{2}{c}{ Early Bloom } & \multicolumn{2}{c}{ Mid Bloom } & \multicolumn{2}{c}{ Late Bloom } \\
\hline & Bumblebee & $\underline{\text { Honeybee }}$ & $\underline{\text { Bumblebee }}$ & $\underline{\text { Honeybee }}$ & Bumblebee & Honeybee \\
$\begin{array}{c}\text { Population } \\
\text { Count }\end{array}$ & 58 & 369 & 40 & 121 & 8 & 41 \\
$\begin{array}{c}\text { Bee } \\
\text { Efficiency }\end{array}$ & 651 & 1299 & 449 & 426 & 90 & 144
\end{tabular}

\section{DISCUSISON}

Pollination services decreased after early blueberry bloom for all sites and measured variables. We hypothesize that this is due to the decline of available Vaccinium flowers as fruits come to replace them (Isaacs \& Kirk 2012). This decline could also be attributable to a number of variables outside the scope of our study, such as the bloom times of other nearby plants. The variation of the species of plants adjacent to each farms' Vaccinium crops could have confounded our population counts. However, we believe that replacement of flowers with fruit had the largest direct impact on population counts. Our observation of 10.8 times as many honeybees and seven times as many bumblebees during early bloom as compared to late bloom is attributable to this loss of foraging resources. It is also important to consider that many of the farms had managed honeybee boxes on or near their sites. This could have impacted the natural habits of wild honeybees and native bumblebees that would otherwise have been on site. Additionally, honeybees may decrease bumblebee foraging efficiency and reproductive success (Hattfield et al. 2012). This increased pressure on bumblebee populations may have led to a decrease in their presence at monitoring sites.

Floral handling rate was also correlated to the number of available flowers. As available flowers decrease, the floral handling rate for honeybees and bumblebees decreases as well. We attributed this to the increased travel time and distance between each flower. As flowers become more scarce, more time is needed to find one that is neither already pollinated nor begun to turn into fruit. This emphasizes the importance of bees during the early stages of the blueberry bloom. 
Not only is the presence of bees important during early bloom, but we also found that the type of bee can make a difference in the effectiveness of pollination. Bee efficiency declined from early to late bloom for both bee groups. In mid bloom, however, bumblebee efficiency was higher than honeybee efficiency. This could be attributed to many factors such as a change to poorer weather conditions. During mid bloom the weather was colder, windier and more overcast than during early and late blooms. We believe the ability to withstand colder temperatures allowed bumblebees to be more active and more effective during mid bloom (Stephen and Rao 2010). Across all farms bumblebees had a population one-fifth the size of honeybees, but were able to pollinate half the total number of flowers observed. This may be due to bumblebees' unique ability to buzz pollinate- a method, which allows for faster and more effective pollination (Javorek et al. 2002). Because bee efficiency is a compilation of population counts and floral handling rate, any change in either variable would directly alter bee efficiency.

In addition to bloom time, we also found that farm size may influence population counts. The large farms in our study contained half the amount of honeybees and 1.7 times the amount of bumblebees as compared with small farms. Walther-Hellwig and Frankl (2000) state that bumblebee flight range is one to two kilometers while honeybees are known to travel up to four and five kilometers. It is possible that because honeybee flight range is much larger than that of bumblebees, honeybees are more likely to forage a larger area and less likely to be concentrated along any single transect.

While our data provided insight into bee pollination activities, it also raised a number of questions that provoke further inquiry. More research is required to understand the potential for increasing pollination services provided by native bees. There were several variables unaccounted for in our study design that could have affected bee populations. Because native bees require specific habitats in order to survive, it is important for farms to provide that high quality habitat. We used a farm assessment protocol to qualitatively evaluate natural pollinator habitat (Native Bee Conservation Pollinator Habitat Assessment Form and Guide 2011) at each farm. A lack of data regarding the history, geology and flora of each site did not allow us to develop an accurate habitat quality assessment score for each farm. This information would allow for efficiency and population data to be cross-referenced with farm assessment scores to build a more comprehensive understanding of the importance of habitat quality on bee presence and pollination efficiency. Expanding the study to determine which species yields higher efficiency rates for other agricultural crops as well as the effects of on-site honeybee hives on bumblebee floral handling rates and populations also would provide valuable information.

This study has introduced an understanding of the role of native bees in providing pollination services to highbush blueberry plants in the Willamette Valley. This data is particularly significant as a baseline for future monitoring and research regarding the role of native bees in pollinating Willamette Valley crops. Bees make up the majority of all insects responsible for the biotic pollination and genetic diversity in plants. As honeybee populations decline, native bees provide an irreplaceable service. Farmers rely on these insects as an economic base for their harvest, while consumers depend on farmers to grow enough food to sustain current levels of food consumption. Therefore it is crucial for farmers to find ways to 
increase their yields by improving the pollination services provided to their crops. The higher pollination efficiency of bumblebees on Vaccinium bushes found in this study implicates the importance of developing farm management practices that actively conserve bumblebee habitat and foraging resources.

In light of our findings, we recommend that farmers in the Willamette Valley take steps to increase native bumblebee populations by developing bumblebee-friendly habitat and forage.

There are various farm management techniques that will promote pollinators foraging and establishing nests on farm property. According to the Xerces Society for Conservation (Native Bee Conservation Pollinator Habitat Assessment Form and Guide, 2011), two important management practices include avoiding both tilling and pesticides. Tilling heavily disturbs ground nesting bee habitats. If tilling is a necessary aspect of the farm, nesting habitats should be maintained in other areas. Alternative methods to traditional tilling can also be used to avoid nesting disturbances. .

Reducing pesticide and herbicide use is another management practice integral to the success of pollinators (Xerces 2011). Ideally, a farm's management plan would include minimal to no pesticide or herbicide use. If pesticides are used, they are best sprayed at night when pollinators are not foraging. Of all pesticides, insecticides are the most damaging to pollinators. Even organic insecticides can harm or kill pollinators that are desired on the farm. Alternatives to conventional herbicides include organic herbicides and management of the weed seed bank in the soil (Mader, personal communication 2012). By killing unwanted plant seeds before they can establish themselves weeds can be eradicated without the use of herbicide. By effectively integrating pollinator conservation strategies in their farm management plans, Vaccinium farmers in the Willamette Valley can increase the pollination services provided them by native bees, increase their crop yields, and reduce their need for purchasing non-native honeybee colonies.

\section{ACKNOWLEDGEMENTS}

Funding for this project was provided by the Katherine Bisbee II Fund of The Oregon Community Foundation. Additional funding, equipment, and technical support provided by the University of Oregon Environmental Studies Program. We would like to thank the Co-Director of the ELP, Peg Boulay, for her guidance and support, Eric Mader (Xerces Society) and Bruce Newhouse for providing us with invaluable background information, as well as our project manager, Raj Vable, for his undivided attention and spirit. Finally, we would like to thank all six blueberry farms that allowed us to monitor on their property: Royal Blue Organics, McKenzie River Farms, Camas Farm, Adkins Farm, The Blueberry Patch, and Burwell Farm. This was a project of the University of Oregon Environmental Leadership Program. 


\section{REFERENCES}

Boulay, P. 2012. 2012 Blueberry Pollination by Native Pollinators Protocol: Revised. UO Environmental Leadership Program.

Boyle, A. 2007. Virus becomes new suspect in bee die-off. Available from http://www.msnbc.msn.com/id/20612274/ns/technology and sciencescience/t/virus-becomes-new-suspect-bee-die-off/\#.T1 g m6pLo (Accessed March 2012).

Evans, E. 2012. The Guide to Identifying the Western Bumble Bee Bombus Occidentalis. The Xerces Society for Invertebrate Conservation.

Hatfield, M., S. Jepsen, E. Mader, S.H. Black, and M. Shephard. 2012. Conserving Bumble Bees: Guidelines for Creating and Managing Habitat or America's Declining Pollinators. Xerces 10.

Hopwood, J., Vaughan, M., Shepherd, M., Biddinger, D., Mader, E., Hoffman Black, S., Mazzacano, C. Are neonicotinoids killing bees? The Xerces Society for Invertebrate

Conservation, Portland, Oregon. Available from http://www.xerces.org/wpcontent/uploads/2012/03/Are-Neonicotinoids-KillingBees Xerces-Society1.pdf (Accessed January 2013).

Javorek, S. K., Mackenzie K. E., and S. P. Vander Kloet. 2002. Comparative Pollination Effectiveness Among Bees (Hymenoptera: Apoidea) on Lowbush Blueberry (Ericaceae: Vaccinium angustifolium) Annals of the Entomological Society of America 95: 345-351.

Kirk, A. K. \& R. Isaacs. 2012. Predicting Flower Phenology and Viability of Highbush Blueberry. HortScience 47: 1291-1296.

Mader, E. Farming for native bees: conservation of native crop pollinators. Lecture, University of Oregon, 9 March 2012.

Native Bee Conservation Pollinator Habitat Assessment Form and Guide. June 2011. Xerces Society for Invertebrate Conservation. Portland, OR. Available from http://www.nm.nrcs.usda.gov/technical/fotg/section-2/wildlife/whegPollinatorHabAssess.pdf (Accessed April 2012).

Pendergrass, K., M. Vaughan, and J. Williams. 2008. Plants for pollinators in Oregon. Unpublished report. Technical Notes: Plant Materials Number 13. U.S.D.A. Natural Resources Conservation Service, Portland, Oregon. Available from http://www.plantmaterials.nrcs.usda.gov/pubs/orpmstn7451.pdf (Accessed March 2012).

Potts, S. G., J. C. Biesmeijer, C. Kremen, P. Neumann, O. Schweiger, and W. E. Kunin. 2010. Global pollinator declines: trends, impacts and drivers. Trends in Ecology and Evolution 25:345-353.

Pywell, R.F., W. R. Meek, L. Hulmes, S. Hulmes, K.L. James, M. Nowakowski, and C. Carvell. 2011. Management to enhance pollen and nectar resources for bumblebees and butterflies within intensively farmed landscapes. Journal of Insect Conservation 15:853864. 
Rao, S. and W. P. Stephen. 2010. Abundance and diversity of native bumblebees associated with agricultural crops: the Willamette Valley experience. Psyche: A Journal of Entomology, Vol. 2010: Article ID 354072. DOI 10.1155/2010/354072.

Ratti, C. M., H. A. Higo, T. Griswold, and M. L. Winston. 2008. Bumble bees influence berry size in commercial Vaccinium spp. cultivation in British Columbia. Canadian Entomologist 140:348-363.

Royal Blueberries. Royal Blueberries farm practices. 2010. Available from http://www.royalblueberries.com/farm practices.htm (Accessed March 2012).

Tuell, J. K., and R. Isaacs. 2010. Weather during bloom affects pollination and yield of highbush blueberry. Apiculture and Social Insects. Journal of Economic Entomology 103:557-562.

Ullmann, K., M. Vaughn, C. Kremen, T. Shih, and M. Shepherd. 2010. California pollinator project: citizen scientist pollinator monitoring guide. Xerces Society for Invertebrate Conservation and University of California Berkeley. Available from http://www.xerces.org/wp-content/uploads/2010/06/CA CSM guide.pdf (Accessed March 2012).

Vaughan, M., M. Shepherd, C. Kremen, and S. Hoffman Black. 2007. Farming for bees: guidelines for providing native bee habitat on farms. Unpublished report. The Xerces Society for Invertebrate Conservation, Portland, Oregon. Available from http://www.xerces.org/wpcontent/uploads/2008/11/farming for bees guidelines xer ces society.pdf (Accessed March 2012).

Walther-Hellwig, K. and R. Frankl. 200o. Foraging habitats and foraging distances of bumblebees, Bombus spp. (Hym., Apidae), in an agricultural landscape. Journal of Applied Entomology 124: 299-306. 